\title{
Debunking the Myths of Psychotherapy
}

\author{
Lubhana Malik Mental* \\ Department of Psychology, University of Delhi, India
}

Submission: Febuary 25, 2019; Published: March 05, 2019

*Corresponding author: Lubhana Malik Mental, Department of Psychology, University of Delhi, India

Keywords: Ambiguity; Depression; Absolutely; Debunking; Turmoil; Recognizing

\section{Opinion}

Just as you would not think twice about immediately consulting a doctor when you have a physical ailment/issue, you should immediately consult a therapist for a mental health concern. But, do you? Most of the times, the answer to this question is a 'No'. The reason may lie in the fact that you are aware of several myths related to therapy, and you may be inclined to be influenced by them. Ambiguity of what therapy is leads to resistance to seek it and a misunderstanding of its process and effectiveness. This blog is aimed at debunking the common myths that are associated with therapy.

\section{People who go for therapy are crazy}

The reality is that the majority of people in therapy are ordinary, everyday people dealing with ordinary, everyday problems. Adjusting to major life changes, experiencing grief, processing anger, improving relationships, working on selfesteem, anxiety, depression, mood fluctuations and addressing core beliefs about one's body image are all examples of common issues that bring people to therapy. There are many other issues people go to therapy for, of course, which likewise are absolutely normal.

\section{Therapy is for the weak}

The general perception people have is that if one is strong, one can fix everything in one's life. When a person is going through an issue in life, just coping with it also requires immense strength. Recognizing that you require therapy requires grit, and so you have mustered courage to face, as well as address your fears and emotional turmoil. That is actually a sign of strength.

\section{Therapy is too expensive and takes forever}

Therapy addresses/heals your emotional/mental issues, which are important for your mental fitness. Addressing your mental health is an investment towards yourself. When mental health is not addressed it starts to manifest itself into physical symptoms. Therapy should not be an unending process, therapy should focus on goals and outcomes, and people should be able to graduate from it. When your therapy goal is met, you will naturally phase out of therapy. Good therapy has an end date. Therapy is temporary because it equips you with tools that last forever. A good therapist wants you to get better and leave therapy, and will teach you skills to use these tools so that you can 'be your own therapist' when you are on your own.

\section{Therapy is common sense}

Common sense is wisdom that manifests itself over time and applies to everyone in the society as a whole. But, therapy provides insight, which is wisdom unique to you as an individual. Therapy provides you a space in which you focus only on yourself with the support of a trained expert who works to understand and guide you to achieve your goals.

\section{Therapy is unnecessary when you can just talk to good friends or family}

There's a pervasive belief in our culture that if you have the support of a good friend and/or a close family member, a talk with him/her can be a substitute for therapy. Social support is important for everyone, especially when you're super stressed. And, you need to understand that you are not deciding to go to a therapist because you don't have a reliable friend. Unlike friends and family, therapists are unbiased to the situation and help you become aware about your contribution to a problem you may be facing. Additionally, they do not offer advice or solutions. Instead they encourage you to consider all possible options so you can make your own decisions. Therapists are highly professionals who diagnose and treat cognitive, emotional, behavioural and relational issues. 
Therapy isn't working unless the process leads to emotional turmoil

Therapy often gets painted as a painful and miserable process. But this picture glosses over the fact that therapy equips clients with effective coping skills to live a more fulfilling life and can be very rewarding, which does not mean it needs to be a painful process.

\section{Therapy entails brainwashing}

Some people believe that therapists push their ideas and agendas on to their clients. However, a good therapist will always help you rediscover or regain your voice, not lose it. Good therapy always starts with creating a safe space to contain everything a client brings, in terms of his/ her belief systems, thoughts, values, perceptions, goals etc. It is about building trust and safety, born from acceptance and 'unconditional positive regard". This simply means that true safety and trust is built on the premise that acceptance exists despite different views and perspectives, so you are not chasing agreeance.

\section{Therapy is just self-indulgence and makes people too focused on themselves}

We do a better job of helping others when we've made sure our own needs are taken care of first. Remember the announcement in airlines that please put on yourself before you place it on your children. If we don't prioritize ourselves, we make other people suffer. It takes a lot of courage to look at yourself, your feelings, and your relationships honestly.

\section{Therapy just makes you dependent on your therapist}

A therapist's goal is to help you reach a point where you ultimately don't need therapy anymore. This is the reason that a therapist will not tell you what to do, rather help you develop the ability to make decisions. A therapist can help you set the process in motion, by helping you identify choices, build decision trees, back-track goals so that gradually you will be equipped to carry on by yourself.

\section{Talking about my problems, especially with a total stranger, won't change anything}

Therapy is about discussing the problems in order to develop a new understanding of them, to explore what caused them or to find out keeps them going, and to consider and experiment with alternative solutions. In other words, to work toward making real changes that will help you feel more satisfied with your life. This requires the intervention of a trained therapist.

\section{Therapy only deals with the past}

This is an exaggerated notion. Therapists focus on helping you with problems you are having today. In some cases, this may require to scan your past to shed light on similar patterns or situations. This information helps us to understand what to do differently so that we can have different outcomes. While sometimes it can be useful to talk about your past, the process of therapy depends on the aims and goals of the client.

If you feel that you are struggling to cope with life, constantly feel sad, empty, helpless, alone or angry, therapy can help you to identify the disconnect and equip you to resolve those issues so that you can live a fulfilling and meaningful life.

\section{Your next submission with Juniper Publishers will reach you the below assets}

- Quality Editorial service

- Swift Peer Review

- Reprints availability

- E-prints Service

- Manuscript Podcast for convenient understanding

- Global attainment for your research

- Manuscript accessibility in different formats ( Pdf, E-pub, Full Text, Audio)

- Unceasing customer service

Track the below URL for one-step submission https://juniperpublishers.com/online-submission.php 